\title{
Developing Higher Order Thinking Skills (HOTS) - Based Questions: Indonesian EFL Teachers' Challenges
}

\author{
Mei Ardaning Tyas ${ }^{1 *}$, Joko Nurkamto ${ }^{1}$, Sri Marmanto ${ }^{1}$ and Hening Laksani ${ }^{1}$ \\ ${ }^{1}$ Graduate School of English Education Department, Sebelas Maret University, Indonesia
}

\begin{abstract}
The significance of critical thinking as one of the $21^{\text {st }}$ century skills makes the Indonesian Ministry of Education and Culture integrate Higher Order Thinking Skill (HOTS) in the latest national curriculum. It requires teachers, as the curriculum implementers, facilitate students to be critical thinkers through the teaching and learning activities. Besides, the teachers need to have competence in developing HOTS - based questions in order to assess the students' HOTS. However, teachers' ability in this field is still disappointing. The aim of this study was to investigate the challenges faced by Indonesia English as Foreign Language (EFL) teachers in developing HOTS based questions. The study employed qualitative method and made use of questionnaire to collect the data. The research participants were EFL teachers of secondary school level in some different regions in Indonesia. The findings showed that, despite the importance of HOTS, some factors were claimed as challenges for the teachers in developing HOTS - based questions, among others was the teachers' varied-perceptions towards HOTS. The challenges were classified into three aspects, namely teachers' aspect, teaching and learning aspects, and students' aspect. Hence, the conclusion was drawn to improve educational practice and as insights for educational stakeholders and policy makers.
\end{abstract}

Keywords: Higher Order Thinking Skills, HOTS, Indonesian EFL Teachers' Challenges, HOTSBased Questions

\section{Introduction}

The rapid development in the $21^{\text {st }}$ century requires people to master some certain skills namely the $21^{\text {st }}$ century skills in order to be able to compete in global competition. Duncan (2009) defines the $21^{\text {st }}$ century skills as the skills that progressively request creativity, persistence, and problem solving combined with performance as part of a team well. Nowadays, education becomes the central attention since it directly contributes to foster people's readiness in facing the global challenges. National Education Association (2012) states that besides having strong content mastery, every student has to own "Four Cs Skills" which also has known as the $21^{\text {st }}$ century skills including critical thinking, communication, collaboration, and creativity. In addition, Larson \& Miller (2012) claims that students need to hold the $21^{\text {st }}$ century skills to enter today's workforce. Therefore, classroom context is required to provide activities that can develop the students' $21^{\text {st }}$ century skills in order to make them able to implement the skills in their daily life so that they will be ready to face the global challenges.

Realizing the urgency of the $21^{\text {st }}$ century skills, the Indonesian national ministries of education and culture includes these skills in the classroom-learning context through the implementation of the latest curriculum, 2013 curriculum (Ahmad, 2014). The $21^{\text {st }}$ century skills are stated in several new educational policies and one of the most crucial policies is the implementation of Higher Order Thinking Skills (HOTS) - based learning. Brookhart (2010) defines higher order thinking into three categories namely transfer, critical thinking, and problem solving. In the term of transfer, students are not only expected to learn the knowledge and skills, but also expected to apply the knowledge and skills to new situations or real life context. Critical thinking requires students to apply wise decision or to make a logical critique. While in the term of problem solving, students are hoped to be able to discover a solution of a certain problem that cannot be simply solved by memorizing. Furthermore, Saavedra \& Opfer (2012) claim that higher order thinking is belonged to the $21^{\text {st }}$ century skills in the way of thinking. 
The integration of the $21^{\text {st }}$ century skills, especially HOTS into teaching-learning activities reaps pros and cons among education stakeholders (Hashim et al., 2018). Collins (2014) states that education stakeholders' awareness about the importance of teaching HOTS are very prominent to guarantee the success of learning. He, further, claims that it is hard to visualize a teacher or a school leader who is not aware of the significance of teaching HOTS to prepare students to live in the $21^{\text {st }}$ century. Despite the importance of HOTS, the extent to which higher order thinking skills are taught and assessed continues to be an area of debate. There is still a lot of confusion that occurs especially in the stages of implementation in class. Besides have to be taught and assessed in all subject matter given at school, the confusion about HOTS is also caused by many factors that occur in the field.

In English as Foreign Language (EFL) subject, the integration of HOTS in the teaching-learning process is closely related to some aspects such as national curriculum policy, textbook availability, teachers, and students' cognitive abilities. It is clear that the national curriculum requires the integration of HOTS in the teachinglearning process of EFL Subject. However, the fact shows that the EFL subject textbook provided by the government is not sufficient to enhance students' skill of higher order thinking. In addition, Jannah (2018) has a claim about teachers' role toward the success a certain education system. They say that teachers are the main contributors to the success of an individual school or education system. As the consequence of textbook limitedness in developing students' HOTS, EFL teachers need to be able to engage their students to the higher order thinking through teaching and learning activities, including providing the students with HOTS - based questions.

Daud (2017) argues that in developing HOTS in a language classroom, teachers would not only need to have subject matter knowledge, but they also have to know what HOTS contains of and how it can be included into the curriculum. However, the study of Yusoff \& Seman (2018) shows that EFL teachers could not give satisfactory explanation about the concept of HOTS. Moreover, not many of them practice asking HOTS - based questions or develop HOTS -based questions. In Indonesian context, Ministry of Education and Culture (2017) claims that teachers need to develop HOTS - based questions since it is essential to prepare students' competence to face the $21^{\text {st }}$ century, foster care and love the regional development, increase students' learning motivation, and improve the quality of assessment.

In an ideal condition, teachers need to provide the students with HOTS - based questions which are related to the Bloom's taxonomy. The latest version Bloom's taxonomy includes remembering, understanding, applying, analyzing, evaluating, and creating (Anderson \& Krathwohl 2001). Mishra \& Kotecha (2016) claim the Bloom's revised taxonomy as reference point to HOTS. They believe that HOTS is represented in the level of analyzing, evaluating, and creating which can be visualized by Figure 1 below:

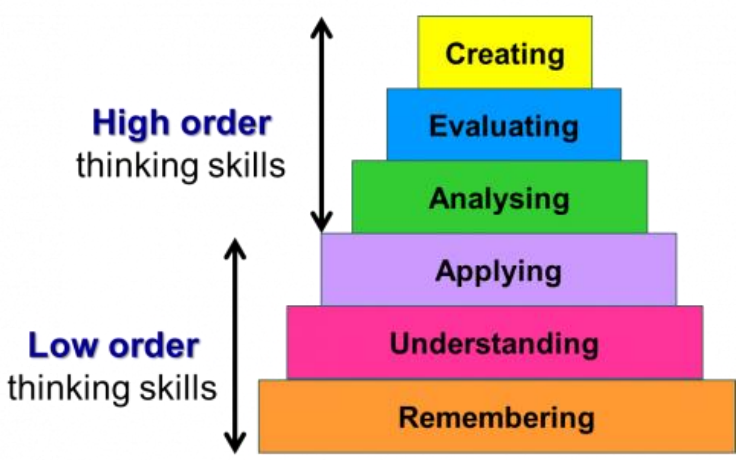

Figure 1:Bloom's revised taxonomy and HOTS (Mishra \& Kotecha, 2016).

By realizing the problem of lack of HOTS in classroom and HOTS - based questions in test paper, Mishra \& Kotecha (2016) observe that the most of the question papers were structured only to assess Lower Order Thinking Skills (LOTS). The fact shows that EFL teachers still find difficulties in making HOTS - based 
questions and it will directly affect the assessment stage of teaching and learning process. The study of Smith \& Szymanski (2013) argues, "The principal needs to make sure that students' performance is assessed on a regular basis as a way of modifying and steering the higher-order thinking program." These kinds of assessment will offer significant feedback for teachers as they support their students' development of HOTS. In addition, Feng (2013) states that EFL teachers should be experts at developing higher order questions to develop their students' critical thinking ability. He, further, says that the questions teachers ask decide the way in which their students' thinking goes. Ayvaz-Tuncel \& Çobanoğlu (2018) believe that teachers need to reflect their own pedagogical competence including planning to the evaluation process at the classroom context. The statement is in line with Moodley (2015) who says that the quality of teachers is measured by their performance in developing good assessment tasks. It means that mastering competence to develop HOTS - based questions is fundamental for teachers.

The study from Seman et al. (2017) reveals that teacher is one of the main factors that influenced success or failure in teaching for HOTS. Moreover, Setyarini et al. (2018) state that teacher's perceptions HOTS plays a crucial role in their attitude towards HOTS - based questions. Due to the importance of teachers' ability in developing HOTS - based questions, this study aimed to investigate the challenges that faced by in-service EFL teachers in developing HOTS - based questions. It becomes the important issue for the research since the challenges faced by teachers in compiling HOTS - based questions are important to highlight because they directly affect the students' HOTS ability. Thus, this research is intended to investigate the challenges faced by Indonesia English as Foreign Language (EFL) teachers in developing HOTS - based questions by formulating two prominent questions which become the guideline in conducting the research: 1) How are in-service EFL teachers' perceptions about HOTS - based question? and 2) What are in-service EFL teachers' challenges in developing HOTS - based questions?. The results of this study are expected to be able to provide insight of alternative solutions that can enhance teachers' competence at developing HOTS - based questions.

\section{Method}

The study investigated in-service EFL teachers' experiences in developing HOTS - based questions by exploring and describing teachers' challenges through qualitative research design. In this section, the explanation was given in details concerning participants, context, instrument, data collection, and data analysis of the study. The study used purposive sampling to select the specific subject having characteristic and criteria being investigated in the study. The sample of the study included 18 in-service EFL teachers from different regions in Central Java and East Java, Indonesia. The objects were senior high school EFL teachers from various schools in different regions which were purposefully chosen by means of their experiences in developing HOTS - based questions. As regards gender, there were 16 female teachers and 2 male teachers. The number of the participants of the study indicated the unbalanced gender distribution of the sample that mostly carried out by female teachers. Additionally, in terms of teachers' age, there were seven teachers aged 25-30 years, five teachers aged 31-35 years, two teachers aged 36-40 years, and four teachers aged 41-51 years. Besides, in terms of teaching experience, there were eleven teachers with 1-7 years of teaching experience, three teachers with 814 years of experience, and four teachers with 15-21 years of experience. This situation indicated that the average of EFL teachers' in Central Java and East Java were well experienced.

In order to investigate the EFL teachers' challenge in developing HOTS - based questions, this study adapted two surveys which had been developed and modified from Choy \& Chea (2009) and Seman et al. (2017) targeting teachers' perceptions and belief on HOTS - based assessment. Based on this framework, the survey comprised nine questions. The items of the survey were in the form of essay questions in order to find specific description by each personal teachers' experiences. The questionnaire asked the teachers about their perceptions and their experiences related to HOTS - based question development and the kind of challenges they found in those processes. The data of demographic characteristics such as gender, age, and teaching experience were also collected in the survey. 
The data were collected in the last 2018 academic years after students had finished the first semester examination in senior high school level. The aim was to be able to collect more teachers' experiences in developing learning assessment. Particularly, the intended results would depict the meaningful and novelty explanation from various teachers' experiences in different schools and different regions in Indonesia. After collecting the data, content data analysis technique (Weber, 1990) was employed to analyze the data. In this case, the responses collected from the participants were classified into several codes in terms of the purpose of the study. The researchers then gathered similar codes into more conceptual categories in order to interpret specific themes emerged from the categories given. Moreover, the data were coded separately and then the categories were compared in order to ensure the consistency and reliability. In terms of the comparison stage, the researchers used inter-rater formula (Miles \& Huberman, 1994) by grouping the collected results of the survey through agree and disagree explanation categories. As the survey used essay coding, the reliability formula was achieved through the separated answers in terms of various categories in terms of the level of teachers' challenges.

\section{Results and Discussion}

Knowing EFL teachers' perception of HOTS - based questions in this study was very important since it could portray their attitude in developing HOTS - based questions as well as the challenges they faced. The data gotten from the questionnaire showed that in-service EFL teachers had some different perceptions about HOTS - based questions and HOTS itself in general. The data analysis and reduction results showed that in-service EFL teachers' knowledge about HOTS was still near to the ground. Most of the teachers gave general explanation about what HOTS is as what has been illustrated in Table 1.

Table 1:Definition of HOTS according to EFL teachers.

\begin{tabular}{|c|c|}
\hline Definition of HOTS according to EFL Teachers & Verification result \\
\hline Problem analysis skills & \multirow{8}{*}{$\begin{array}{l}\text { Not all EFL teachers understood the } \\
\text { concept of HOTS well. They were still } \\
\text { confuse about distinguishing skills for } \\
\text { HOTS and skills to solve difficult } \\
\text { problems. }\end{array}$} \\
\hline Ability to solve problems with various ways & \\
\hline Ability to solve difficult problems well & \\
\hline $\begin{array}{l}\text { Thinking skills that is more than just memorizing and } \\
\text { reading }\end{array}$ & \\
\hline Analysis skill to answer difficult questions & \\
\hline High reasoning skill in answering complex questions & \\
\hline $\begin{array}{l}\text { Critical thinking, logical thinking, and creative thinking to } \\
\text { solve problems that students have not faced before }\end{array}$ & \\
\hline $\begin{array}{l}\text { Higher order thinking skills which involve the process of } \\
\text { analyzing, evaluating, and creating }\end{array}$ & \\
\hline
\end{tabular}

The result indicated that most of the EFL teachers still misunderstood the concept of HOTS. It can be seen by the statements of some teachers that they were still confuse about distinguishing skills for higher order thinking and skills for solving difficult problems. They assumed that HOTS - based questions are always difficult to be solved. It is in line with the study of Retnawati et al. (2018). They claim that Indonesian teachers especially in mathematic subject still misconceive HOTS concepts. It could portray the teachers' understanding about HOTS 
in general that not all the teachers of any subject matters, including EFL, understand the concept of HOTS well. The statement could be supported by the verification result in Table 1. This misconception led the EFL teachers to develop difficult questions instead of HOTS - based questions. They tended to assume that HOTS - based question is the question which categorized as complex or difficult questions, whereas based on some experts, HOTS - based question is not always the difficult one, and vice versa (Brookhart (2010), Conklin (2012), Mishra \& Kotecha (2016)). Related to this finding, it is crucial to understand that the knowledge of HOTS is the EFL teachers' basic weapon in order to be able to integrate HOTS in the process of teaching and learning, whether in planning stage, implementation stage, and evaluation stage. As what have stated before that teachers' knowledge of HOTS plays a crucial role in their attitude towards the implementation of HOTS itself (Setyarini et al., 2018), having the right conception of HOTS will be truly beneficial for teachers in engaging their students' HOTS in the learning process. It will be useful for students as well since teachers with good HOTS conception will direct them to the HOTS competence. When the EFL teacher has a great understanding of HOTS and the students' HOTS can be cultivated, it means that the goal of Indonesian Ministry of Education and Culture can be achieved satisfyingly.

In addition, the finding showed that the in-service EFL teachers agreed about the importance of HOTS implementation in the classroom context. All the participants believed that HOTS was prominent to be owned by students to be success in the global era. In addition, teachers already knew that students' HOTS could be improved by providing them a good teaching-learning environment including giving them HOTS - based questions. They believed that HOTS - based questions could engage students in the thinking process which requires HOTS so that they could answer the questions well. HOTS - based question can be found in the EFL subject textbooks, it can be developed by teachers themselves in order to facilitate their students HOTS development as well. However, due to the fact of Indonesian EFL textbooks limitedness in facilitating students' HOTS, teachers need to have ability in developing HOTS - based questions. It means that the teachers have good awareness of the important of HOTS for students. In spite of teachers' awareness of the importance of HOTS for the students, they were still lacking in good knowledge on learning and improving students' HOTS. This fact would directly affect the implementation of HOTS in the teaching-learning process since Collins (2014) states that teachers' awareness about the importance of teaching HOTS and their knowledge of HOTS are very prominent to guarantee the success of students' learning. Nevertheless, he further, claims that it is hard to visualize a teacher who has inadequate knowledge of HOTS to prepare students to live in the 21st century. By seeing the result in Table 1, it is assumed that the teachers will find difficulties to prepare students to live in the 21 st century due to their inadequate knowledge. Since, a good awareness of the importance of HOTS is not sufficient to support the students to develop their HOTS; the teachers are also required to have a great knowledge and understanding of HOTS in order to assist their students in cultivating HOTS.

Employing purposive sampling technique, this research resulted in the participants who already had experience in developing HOTS - based questions. Some of the EFL teachers stated that they had joined some related workshops about the implementation of HOTS in the classroom. While some others claimed they had joined neither training nor workshop that was related to HOTS - based questions development. However, all of them claimed that they were required to implement HOTS in their classroom and to develop HOTS - based questions for their students. It means that they are already familiar with the implementation of HOTS in the teaching and learning process, including the process of HOTS - based questions development. However, all the participants argue that they still found difficulties in developing HOTS - based questions. Furthermore, they mentioned some challenges that they faced in developing HOTS - based questions. Three main results were highlighted in this study including teachers' experience in developing HOTS - based question, considered aspects in developing HOTS - based questions, and aspects they need in developing HOTS - based questions. Those three results were emphasized since they play very crucial role in the successfulness of the teachers in developing HOTS - based questions. 
The first result is related to the experience in developing HOTS - based questions, all participants said that they had already developed HOTS - based questions. Some of them said that they had joined the workshop of 2013 curriculum; the workshop itself was divided into some activities including the training in developing HOTS based questions. While some others claimed they had joined neither workshops nor trainings related to 2013 curriculum and HOTS. This fact got them to have difference experience in HOTS - based questions development. The EFL teachers who had joined workshops or training about HOTS argued that they were helped by the knowledge they got from those workshops or training at developing HOTS - based questions. While they who did not have experience in joining workshops or trainings of HOTS stated that they were still confuse in understanding the concept of HOTS and found a lot of difficulties in developing HOTS - based questions. It means that joining workshops or training about HOTS could facilitate the teachers to develop their skills to develop HOTS - based questions.

Having asked whether they found any difficulties or challenges in developing HOTS - based questions or not, the teachers who had already joined workshop and who had not both said that they still face some challenges that made them difficult to develop HOTS - based questions. That is to say that joining workshops or training related to HOTS did not make them experts in developing HOTS - based questions since they still face challenges and difficulties in the process of HOTS - based questions development. They claimed several factors that challenge them in HOTS - based questions development. The main factors which became challenges for the EFL teachers are presented in Table 2.

Table 2:Factors that challenge EFL Teachers in developing HOTS - based questions.

\begin{tabular}{|c|c|}
\hline $\begin{array}{l}\text { Factors that challenge EFL Teachers in } \\
\text { developing HOTS - based questions }\end{array}$ & Verification result \\
\hline $\begin{array}{l}\text { Limited understanding about the concept of } \\
\text { HOTS and HOTS - based assessment }\end{array}$ & \multirow[t]{4}{*}{$\begin{array}{l}\text { EFL teachers still faced some } \\
\text { challenges that made them } \\
\text { difficult to develop HOTS - } \\
\text { based questions. }\end{array}$} \\
\hline Limited resources of learning & \\
\hline $\begin{array}{l}\text { Limited experience in developing HOTS - based } \\
\text { questions }\end{array}$ & \\
\hline $\begin{array}{l}\text { Students' competence and the difficulty level of } \\
\text { EFL subject materials }\end{array}$ & \\
\hline
\end{tabular}

Based on the results displayed in Table 2, there were six aspects which mainly challenge teachers in developing HOTS - based questions. The first aspect was the teachers' own understanding about the concept of HOTS. Since understanding and implementation have a strong bond, it will directly affect their competence in developing HOTS - based questions. It is in line with the statement of Sulaiman et al. (2017) who state that teachers need to understand what higher order thinking skills entail first only then they will be able to apply the knowledge in teaching and assessing HOTS. It proves that when teachers have limited knowledge about higher order thinking, they will find difficulties in developing HOTS - based questions. In addition to the lack of understanding of HOTS concept, the teachers also did not understand HOTS-based assessment well. Some of the EFL teachers claimed that they could not apply Bloom's taxonomy objective that is related to the HOTS. According to the further investigation, they were still fixated on the use of Lower Order Thinking Skills (LOTS) in developing questions for their students. It is in accordance with the fact that most of the question papers in EFL context were structured only to assess LOTS (Mishra \& Kotecha, 2016). It means that even though the teachers claim that they had understanding about how to develop HOTS, the teachers tended to develop LOTS based questions instead of HOTS - based questions. 
The second aspect, which was claimed by the most participants, was the limited source of learning. Source of learning here means the source that can be used as guideline by the teachers to improve both their understanding about HOTS and their competence in developing HOTS - based questions. The result showed that EFL teachers' challenges or difficulties in developing HOTS - based question were because there was no enough resource for the teachers. Based on the participants' recognition, the availability of learning sources would help them a lot to enhance their ability in developing HOTS - based questions. However, the fact showed that the Indonesian education stakeholders did not provide sufficient resources yet to the EFL teachers in the form of workshops, trainings, and modules. It can be said that the existing workshops, trainings, and modules were inadequate to support the teachers well.

The EFL teachers' limited experience in developing HOTS - based questions became the third aspect that affected their ability in developing HOTS - based questions. It is regarding the fact that the integration of HOTS in the teaching-learning process belongs to a new policy in Indonesian national education system. EFL teachers were not familiar with HOTS yet since they did not learn about it in their university study. Teachers' lack of HOTS knowledge and experience made them difficult when they were asked to implement it in the classroom context including developing HOTS - based questions. It is understandable that teachers need to be more familiarize with HOTS through the great collaboration and support from all educational stakeholders.

The fourth aspect which affected teachers' ability in developing HOTS - based questions was students' cognitive competence and the difficulty level of EFL subject materials as well. Knowing the fact that students in the classroom were heterogeneous got the teachers to think twice while developing HOTS - based questions. Heterogeneous in this case means that students have different cognitive level of competence, it will directly affect their ability in answering the question especially HOTS - based questions. Besides, the difficulty level of EFL subject materials added the complexity of developing HOTS - based questions for the students. The teachers said that students' cognitive competence played a crucial role for students in answering HOTS - based questions. In EFL subject, giving students HOTS - based questions means asking them to be critical thinkers as well as a good language users. For the students with good cognitive competence, it seems easier to answer the questions whether it is in LOTS or HOTS. However, the result will be different for the students who have poor or low cognitive competence. They will be forced to survive in two things at the same time, understanding the language aspects and thinking how to answer it critically. The result of this study is also supported by the research of Singh et al. (2018) which argues that weak English as second or foreign language learners need special treatment in the teaching-learning process. Hence, EFL teachers need to make wise decision about appropriate teaching pedagogy as well as questions for assessment to apply HOTS in the teaching-learning context.

Having answered the questions about the challenges that they faced in developing HOTS - based question, the participants then were asked about the aspect that became their consideration in developing HOTS - based questions. There were several considered aspects which claim by most of the teachers as presented in Table 3 below: 
Table 3: Considered aspects in developing HOTS - based questions.

\begin{tabular}{ll}
\hline Considered aspects in developing HOTS - based questions & Verification result \\
\cline { 1 - 1 } Students' reading comprehension & $\begin{array}{l}\text { The EFL teachers had an agreement on } \\
\text { the considered aspects in developing } \\
\text { HOTS - based questions. }\end{array}$ \\
\cline { 1 - 2 } Students' cognitive competence and critical thinking & \\
\cline { 1 - 2 } Difficulty level and the suitability of the materials & \\
\hline The availability of learning sources for students & \\
\hline Students' real life context and environment &
\end{tabular}

The EFL teachers actually mentioned more than one considered aspects in developing HOTS - based questions, but the aspects listed in the Table 3 were the most widely mentioned aspects. The teachers had an agreement that students' reading comprehension was one of the most important considerations when they were developing HOTS - based questions. Besides students' reading comprehension, students' cognitive competence in general was also mentioned as the significance aspect. Students' cognitive competence, critical thinking, and reading comprehension were important to be considered by EFL teachers. The statement from the teachers is in accordance with Dwyer et al. (2014) who identifies that before capable in the critical thinking; students need to comprehend the information given to them first. Further, as the explanation of the stages in Bloom's Taxonomy from Anderson \& Krathwohl (2001) and Mishra \& Kotecha (2016), before entering the stage of HOTS which include analyzing, evaluating, and creating, the students need to master the previous cognitive competence in remembering, understanding, and applying which are categorized as LOTS. In other word, in English subject, students need to understand and comprehend the language first before they can develop their HOTS. In fact, comprehending English for Indonesian students is not an easy work since it is a foreign language in Indonesia. This fact led the teachers to mention it as one of the considered aspects in developing HOTS - based questions.

The next EFL teachers' agreement was the difficulty level and the suitability of the materials. Seeing difficulty level and the suitability of the materials were important when developing HOTS - based questions, teachers also claimed that analyzing the basic competence and making blueprint as the considered aspects. Analyzing basic competence and making blueprint would facilitate teachers in developing the right assessment for the students. Thus, in developing HOTS - based questions and HOTS - based assessment teachers need to make sure that the questions have good content validity. In addition, teachers believed that environment and students' real life context were the crucial aspects in teaching-learning activities so that they needed to make sure that HOTS based question that they developed were in line with what students needed in their environment and real life context. It is supported by the study of Lee (2014) which states that social presence is positively related to the quality of cognitive presence that will affect the ability of HOTS. It means that it is important to provide students with good study environment inside and outside the classroom in order to foster the process of students' HOTS development.

Being asked about the supported aspects needed in developing HOTS- based questions, most of the teachers gave various explanations that subjectively related to the internal and external conditions which is explained in Table 4: 
Table 4:Supported aspects needed in developing HOTS- based questions.

\begin{tabular}{|c|c|}
\hline Supported aspects needed by the EFL teachers & Verification result \\
\hline EFL teachers' motivation & \multirow{4}{*}{$\begin{array}{l}\text { EFL teachers proposed two major } \\
\text { aspects of the supported aspect } \\
\text { needed in developing HOTS-based } \\
\text { question, namely: internal and } \\
\text { external factors. }\end{array}$} \\
\hline $\begin{array}{l}\text { EFL teachers' understanding of Pedagogical Content } \\
\text { Knowledge and HOTS viewpoint }\end{array}$ & \\
\hline $\begin{array}{l}\text { EFL teachers' program through workshop in the } \\
\text { concept of HOTS }\end{array}$ & \\
\hline $\begin{array}{l}\text { Availability of material and media to support teaching } \\
\text { and learning }\end{array}$ & \\
\hline
\end{tabular}

According to the result presented in Table 4, there were four aspects which mainly proposed by the teachers as the supported aspects needed in developing HOTS - based questions. The three aspects proposed by the teachers were relatively related to the internal factor, namely the teachers' self-development and knowledge. The first aspect needed was the EFL teachers' self-motivation to learn and to develop HOTS - based questions. As a facilitator and controller in teaching learning environment, the teachers' awareness to motivate themselves to learn tends to provide further avenues into students' engagement and desire for educational activities and outcomes (Öqvist \& Malmström, 2018). It indicates that, actually, besides up warding motivation from their own self, the teachers also need to be supported by the environment to increase their awareness and motivation to learn and to develop HOTS - based questions. Since the result will be greater when there is motivation from inside and outside the teachers themselves.

Furthermore, the second supported aspect needed was the teachers' pedagogical content knowledge and the teachers' understanding on HOTS - based instructions. It proves that in teaching learning activities, teachers' perception and understanding of such cases affect to the teaching and learning instructions (Fauziati, 2017). In this sense, teachers said that in order to minimize the misconceptions of HOTS - based questions, further, the teachers are required to understand the subject matter and understand the viewpoint of HOTS because teachers have become the main factors that influence the success or failure in applying HOTS in the classroom (Seman at al., 2017). In addition, some EFL teachers also stated that they needed to be more aware on the students' competences and students' needs in order to successfully implement HOTS in the classroom. Good teachers' pedagogical content knowledge and understanding on HOTS - based instructions will be great matched with good teachers' awareness on students' competence and students' needs in order to apply HOTS in the classroom well.

The two previous mentioned concepts affected the third supported aspect which was needed in developing HOTS-based question, namely teachers' program through workshops or trainings related to HOTS and HOTS based questions which is classified to external factor. Some teachers argued that the knowledge and the understanding of HOTS needed to be shared through workshops or trainings in order to gain the correct concept of HOTS because they claimed that the existing workshops or trainings are insufficient to support them develop their knowledge and understanding of HOTS. Seman et al. (2017) argue that the consequences of not having correct understanding and knowledge of HOTS lead to inability to master the skills of higher order thinking and inability to design and implement effective instructions during teaching and learning sessions. Therefore, the correct concept of HOTS will lead to the correct teaching and learning instruction and assessment. The finally yet importantly, the teaching environment was believed to have a significant impact as one of the supported aspects in developing HOTS - based questions. It was undeniable that the learning process affects the result of the teaching and learning objectives. In this matter, some teachers claimed that the availability of supported materials and media affect directly to the succession of the learning objectives, particularly in terms developing 
test instruction. Hence, further research is expected to examine materials and media used by Indonesian EFL teachers related to HOTS - based questions or exercises contained on it. Additionally, it is also important to investigate Indonesian EFL teachers' practices on teaching HOTS to the students.

\section{Conclusion}

This study was conducted to explore EFL teachers' perception and the challenges face by the EFL teachers in developing HOTS - based questions. The analysis of the data revealed that the challenges were classified into three aspects, namely teachers' aspect, teaching and learning aspects, and students' aspect. Based on the three headings of the factors that challenge the EFL teachers, several conclusion can be drawn.

First, despite of the importance of HOTS - based instruction, EFL teachers tended to face some challenges in implementing and developing HOTS - based questions in the classroom. In this matter, this study demonstrated that the EFL teachers had three major challenges in developing HOTS - based questions. The first challenge occurred as a means of EFL teachers' challenge in terms of limited understanding about the concept of HOTS and HOTS - based questions. Furthermore, the lack of understanding about its concept led to the limited experience in developing HOTS-based assessment. The next challenge was about the teaching and learning process which emerged in terms of the limited resources of learning, such as the teaching materials. The last challenge was the students' factors in terms of heterogeneity of cognitive competence that result to the difficulty on developing appropriate instructions. However, the lack of knowledge and experience that teachers had, were believed to be the dominant challenges faced by the teachers in developing HOTS-based assessment.

Second, the demographic factors including age, gender, and year of teaching experience did not bring significant differences on their perceptions in developing HOTS - based questions. Indeed, teachers with different demographic factors still had the same perceptions and faced the same obstacles in developing HOTS - based questions. Concisely, this study found that internal factors in terms of teachers' aspects were the prominent challenge faced by in-service EFL teachers in developing HOTS - based questions. Therefore, EFL teachers need to master various kinds of fields in order to be skillful and relevant in teaching and learning process in order to deal with the challenges of HOTS development, especially the development of HOTS - based questions.

To sum up, this research had discovered the perceptions and challenges faced by EFL teachers in developing HOTS - based questions. The findings could have important implications for ensuring the successful and effective development of HOTS in the classroom. Hence, school authorities must consider the internal and external factors that effect to its development, for instance through the regular programs of workshops and the investment supports to the teaching materials and media in the classroom. As a part of national education goal in Indonesia, the task to success the integration of HOTS in the process of teaching and learning have to be the responsibilities of all educational stakeholders, especially the government as the policy makers. Besides making the policy regarding to the integration of HOTS, the government also needs to provide teachers continuous training and supervision, as well as modules regarding to HOTS integration including HOTS - based questions development and materials to support the integration of HOTS in the teaching and learning process. As the teachers mentioned that they need teaching material such as in the form of textbooks to support the implementation of HOTS in the classroom, further research is hoped to be conducted to examine the existing textbooks used by Indonesian EFL teachers regarding HOTS - based exercises or questions contained on the textbooks.

\section{Acknowledgement}

A sincere gratitude is expressed to Lembaga Pengelola Dana Pendidikan (LPDP), Indonesia Endowment Fund for Education, for sponsoring the research. Special thanks are also delivered to all parties who have contributed 
to the success of this research, especially Sebelas Maret University and the EFL teachers as the participants of the research.

\section{References}

Ahmad, D. (2014). Understanding the 2013 curriculum of English teaching through the teachers' and policymakers' perspectives. International Journal of Enhanced Research in Educational Development (IJERED), 2(4), 6-15.

Anderson, L. W., \& Krathwohl, D. R. (2001). A Taxonomy for Learning, Teaching, and Assessing: A Revision of Bloom 's Taxonomy of Educational Objectives. Spring, 83(4), 212-220.

Ayvaz-Tuncel, Z., \& Çobanoğlu, F. (2018). In-service Teacher Training: Problems of the Teachers as Learners. International Journal of Instruction, 11(4), 159-174. https://doi.org/10.12973/iji.2018.11411a

Brookhart, S. M. (2010). How to assess higher-order thinking skills in your classroom. ASCD.

Choy, S. C., \& Cheah, P. K. (2009). Teacher perceptions of critical thinking among students and its influence on higher education. International Journal of Teaching and Learning in Higher Education, 2(20), 198-206.

Collins, R. (2014). Skills for the 21st Century: teaching higher-order thinking. Curriculum \& Leadership Journal, 12(14).

Conklin, W. (2012). Higher-order thinking skills to develop 21st century learners. Shell Education Publishing, Inc.

Daud, N. M. (2017). Integrating Hots Into Language Classes in the 21 St. The First Education and Language International Conference Proceedings Center for International Language Development of Unissula, 29-36.

Duncan, A. (2009). Statement from US Secretary of Education Arne Duncan on results of NAEP Arts 2008 assessment. Retrieved from www.ed.gov/news/pressreleases/2009/06/06152009.html.

Dwyer, C., Hogan, M., \& Stewart, I. (2014). Dwyer, C., Hogan, M., \& Stewart, I. (2014). 'An integrated critical thinking framework for the 21st century'. Thinking Skills \& Creativity, 43-52.

Fauziati, E. (2017). Teaching English as a Foreign Language (TEFL II): Principle and Practice. Surakarta: Era Pustaka Utama.

Feng, Z. (2013). Using Teacher Questions to Enhance EFL Students' Critical Thinking Ability. Journal of Curriculum and Teaching, 2(2), 147-153. https://doi.org/10.5430/jct.v2n2p147

Hashim, H., Ali, M. N., \& Shamsudin, M. A. (2018). Infusing High Order Thinking Skills (HOTs) through Thinking Based Learning (TBL) during ECA to enhance students interest in STEM. International Journal of Academic Research in Business and Social Sciences, 7(11), 1191-1199. https://doi.org/10.6007/ijarbss/v7i11/3557

Jannah, S. M. (2018). TEACHERS' BELIEFS ON TEACHING READING TO ACHIEVE HIGHER ORDER THINKING SKILLS (HOTs): A CASE STUDY AT SMA ABBS SURAKARTA. Retrieved from http://eprints.ums.ac.id/59981/12/02 PUBLICATION MANUSCRIPT.pdf

Larson, L. C., \& Miller, T. N. (2012). 21st Century Skills: Prepare Students for the Future. Kappa Delta Pi Record, 47(3), 121-123. https://doi.org/10.1080/00228958.2011.10516575

Lee, S. M. (2014). The relationships between higher order thinking skills, cognitive density, and social presence in online learning. Internet and Higher Education, 21, 41-52. https://doi.org/10.1016/j.iheduc.2013.12.002

Miles, M. B., \& Huberman, A. M. (1994). Qualitative data analysis. Thousand Oaks, CA: SAGE.

Ministry of Education and Culture. (2017). Modul Penyusunan Soal Higher Order Thinking Skills (HOTS). Jakarta: Ministry of Education and Culture.

Mishra, R., \& Kotecha, K. (2016). Are we there Yet! Inclusion of Higher Order Thinking Skills (HOTs) in Assessment. Journal of Engineering Education Transformations, 0(0), 2-5. https://doi.org/10.16920/jeet/2016/v0i0/85686

Moodley, V. (2015). In-service teacher education: asking questions for higher order thinking in visual literacy. South African Journal of Education, 33(2), 1-18. https://doi.org/10.15700/saje.v33n2a430 
National Education Association. (2012). Preparing 21st century students for a global society: An educator's guide to the "Four Cs." Alexandria, VA: National Education Association.

Öqvist, A., \& Malmström, M. (2018). What motivates students? A study on the effects of teacher leadership and students' self-efficacy. International Journal of Leadership in Education, 21(2), 155-175. https://doi.org/10.1080/13603124.2017.1355480

Retnawati, H., Djidu, H., Kartianom, Apino, E., \& Anazifa, R. D. (2018). Teachers' knowledge about higherorder thinking skills and its learning strategy. Problem of Education in the 21st Century, 76(2), 215-230. Retrieved from http://oaji.net/articles/2017/457-1524597598.pdf

Saavedra, A. R., \& Opfer, V. D. (2012). Learning 21st-century skills requires 21st-century teaching. Phi Delta Kappan, (October), 8-13. https://doi.org/10.1177/003172171209400203

Seman, S. C., Yusoff, W. M. W., \& Embong, R. (2017). Teachers Challenges in Teaching and Learning for Higher Order Thinking Skills (HOTS) in Primary School. International Journal of Asian Social Science, 7(7), 534-545. https://doi.org/10.18488/journal.1.2017.77.534.545

Setyarini, S., Muslim, A. B., Rukmini, D., Yuliasri, I., \& Mujianto, Y. (2018). Thinking critically while storytelling: Improving children's HOTS and English oral competence. Indonesian Journal of Applied Linguistics, 8(1), 189-197. https://doi.org/10.17509/ijal.v8i1.11480

Singh, C. K. S., Singh, R. K. A., Singh, T. S. M., Mostafa, N. A., \& Mohtar, T. M. T. (2018). Developing a Higher Order Thinking Skills Module for Weak ESL Learners. English Language Teaching, 11(7), 86. https://doi.org/10.5539/elt.v11n7p86

Smith, V. G., \& Szymanski, A. (2013). Critical Thinking: More Than Test Scores. NCPEA International Journal of Educational Leadership Preparation, 8(2), 16-26.

Sulaiman, T., Muniyan, V., Madhvan, D., Ehsan, S. D., Persekutuan, W., \& Lumpur, K. (2017). International Research Journal of Education and Sciences ( IRJES ). International Research Journal of Education and Sciences (IRJES), 1(1), 2550-2158. Retrieved from www.masree.info Manuscript

Weber, R. P. (1990). Basic content analysis (Vol. 49). SAGE.

Yusoff, W. M. W., \& Seman, S. C. (2018). Teachers' Knowledge of Higher Order Thinking and Questioning Skills: A Case Study at a Primary School in Terengganu, Malaysia. DEVELOPMENT, 7(2). 